\title{
Proceeding
}

Performance Analysis Workshop, 2 - 5 April 2013, Alicante, Spain

\section{Is the date of birth an advantage/ally to excel in handball?}

\author{
CARLOS SÁNCHEZ-RODRÍGUEZ ${ }^{1}$, IGNACIO GRANDE², JAVIER SAMPEDRO², JESUS RIVILLA- \\ GARCÍA ${ }^{2}$ \\ 1 University of Leon, Leon, Spain \\ 2 Polytechnic University of Madrid, Madrid, Spain
}

\begin{abstract}
Sánchez-Rodríguez C, Grande I, Sampedro J, Rivilla-García J. Is the date of birth an advantage/ally to excel in handball? J. Hum. Sport Exerc. Vol.8, No. Proc3, pp. S754-S760, 2013. The Relative Age Effect (RAE) has been analyzed in a population of Spanish international handball players $(n=161)$ divided into four different levels: Senior, Junior, Juvenile and Promising Talents. The variables registered were quarter, half year and year of birth using the initial information of their date of birth. The data were collected from the Royal Spanish Handball Federation on-line data base. The statistical method used was the $\chi^{2}$ and the minimum level of significance was set at $p<0.05$. The total results on distribution by quarter show a significant difference $\left(\chi^{2}=21.68 ; p<0.01\right)$ with a greater frequency of players born in the first quarter $(40.37 \%)$ compared to those born in the second $(22.36 \%)$, third $(16.15 \%)$ and fourth quarter $(21.12 \%)$. The total results on the distribution of birth date by half year show a significant difference $\left(\chi^{2}=10.44 ; p<0.01\right)$ with a greater frequency of players born in the first half of the year $(62.73 \%)$. With regard to the rate of births registered in an even numbered or odd numbered year there are significant differences when the rates for an even numbered year $(64.60 \%)$ and an odd numbered year (35.40\%) are compared with those of the general population $\left(\chi^{2}=13.72 ; p<0.001\right)$. Based on the data collected and analyzed it can be concluded that there is a RAE in the basic categories of the Spanish national men's handball teams according to quarter, half year and year of birth (even or odd numbered), but there exists little knowledge about the causes and consequence which may be produced by, or derive from, this effect. Key words: RELATIVE AGE EFFECT (RAE), TALENT, SELECTION, DETECTION, IDENTIFICATION, SPORT.
\end{abstract}

Corresponding author. Department of Sports, Faculty of Physical Activity and Sports Sciences, Polytechnic University of Madrid, 28040, Madrid, Spain.

E-mail: jesus.rivilla@upm.es

Performance Analysis Workshop, 2 - 5 April 2013, Alicante, Spain

JOURNAL OF HUMAN SPORT \& EXERCISE ISSN 1988-5202

(c) Faculty of Education. University of Alicante

doi:10.4100/jhse.2013.8.Proc3.22

VOLUME 8 | Proc3 | 2013 | S754 


\section{INTRODUCTION}

In sports competitions for children and adolescents the players are divided into categories according to their year of birth. The aim is to promote fair competition with equal opportunities for all the players (Musch \& Grondin, 2001). However, if the categories are established only in reference to the year of birth, players who were born in the month of January are included in the same category as players born in the month of December although they are eleven months older. This can lead to situations of disadvantage for some players compared with others, due to the different levels of growth, maturation and development. In fact, there is evidence that when players are divided according to the half year in which they were born, within the same year, those who were born in the first half of the year have greater emotional (Malina, 1994), motivational (Dixon et al., 2011) and physical development (Delorme \& Raspaud, 2009) than those who were born in the last half of the year. This in turn means that the more developed players have much greater possibilities to reach the elite level (Nolan \& Howel, 2010). In the literature this effect has been called the Relative Age Effect, (RAE), and has been demonstrated in several sports like volleyball (Okazaki et al., 2011), football (Mújica et al., 2009; Romann \& Fuchslocher, 2011) and basketball (Delorme et al., 2011). In spite of having been widely studied there are few articles on this effect with regard to international handball (Baker et al., 2009; Delorme et al., 2009; Gutiérrez et al., 2012; Lidor et al., 2010; Nakata \& Sakamoto, 2011; Schorer et al., 2010; Schorer et al., 2009) and only one study has been carried out on Spanish men's handbally (Sánchez-Rodríguez et al., 2012).

Bearing in mind the important repercussions and practical applications which it entails, as well as the scarcity of studies carried out in the field of Spanish handball, it would seem to be of interest to look more closely at the relative age effect in the different categories of the Spanish national men's handball teams.

\section{MATERIAL AND METHODS}

The analysis was carried out with the data on the population of Spanish international handball players $(n=161)$ in four different categories: (1) Senior ( $n=49$, over 20 year olds), (2) Junior ( $n=48,19-20$ year old), (3) Juvenile ( $n=33,17-18$ year old) and (4) Promising Talents $(n=31,15-16$ year old). All the players selected were Spanish nationals. The following variables were recorded from the initial information on their date of birth:

- Quarter of birth: Differentiating among first (January-March), second (April-June), third (July to September) and fourth (October-December) quarter.

- Half year of birth: Differentiating between first (January-June) and second half year (JulyDecember).

- Year of birth: Differentiating between even and odd numbered years.

The data were compiled by consulting the Royal Spanish Handball Federation on-line data base (http://www.rfebm.net/index.asp\#).

The statistical method used was the $\chi^{2}$ test which shows the difference between the distribution of birth dates observed and the expected distribution of birth dates. The data were analyzed for the total population studied and then by the different groups according to level. The minimum level of significance was set at $p<0.05$. 


\section{RESULTS}

The total results of the distribution of birth date by quarter (Table 1) show a significant difference $\left(\chi^{2}=\right.$ $21.68 ; p<0.01)$ with the greatest frequency of players being born in the first quarter $(40.37 \%)$ compared with those born in the second $(22.36 \%)$, third (16.15\%) and fourth quarter $(21.12 \%)$.

Table 1. Data on the distribution of births by quarter

\begin{tabular}{|c|c|c|c|c|c|c|c|c|c|c|}
\hline \multirow[t]{2}{*}{ LEVEL } & \multicolumn{2}{|c|}{$\begin{array}{c}\text { SENIOR } \\
(n=49)\end{array}$} & \multicolumn{2}{|c|}{$\underset{(n=48)}{J U N I O R^{*}}$} & \multicolumn{2}{|c|}{$\underset{(n=33)}{J U V E N I L E}$} & \multicolumn{2}{|c|}{$\begin{array}{c}\text { PROMISING TALENTS * } \\
(n=31)\end{array}$} & \multicolumn{2}{|c|}{$\underset{(n=161)}{\text { TOTAL * }}$} \\
\hline & $\mathrm{n}$ & $\%$ & $\mathrm{n}$ & $\%$ & $n$ & $\%$ & $n$ & $\%$ & $n$ & $\%$ \\
\hline First quarter & 14 & $28.57 \%$ & 25 & $52.08 \%$ & 13 & $39.39 \%$ & 13 & $41.94 \%$ & 65 & $40.37 \%$ \\
\hline Second quarter & 9 & $18.37 \%$ & 10 & $20.83 \%$ & 7 & $21.21 \%$ & 10 & $32.26 \%$ & 36 & $22.36 \%$ \\
\hline Third quarter & 8 & $16.33 \%$ & 2 & $4.17 \%$ & 10 & $30.30 \%$ & 6 & $19.35 \%$ & 26 & $16.15 \%$ \\
\hline Fourth quarter & 18 & $36.73 \%$ & 11 & $22.92 \%$ & 3 & $9.09 \%$ & 2 & $6.45 \%$ & 34 & $21.12 \%$ \\
\hline$x^{2}$ & & & $x^{2}=2$ & $3 ; p<0.001$ & & & - $x^{2}=$ & $; p<0.05$ & $r^{2}=2$ & $3 ; p<0.001$ \\
\hline
\end{tabular}

This difference does not appear at all competitive levels being equally significant in the case of Promising Talents $\left(\chi^{2}=8.87 ; p<0.05\right)$ and especially Juniors $\left(\chi^{2}=22.83 ; p<0.001\right)$. The results stand out in the junior category with $52.08 \%$ being born in the first quarter compared with only $4.17 \%$ in the third quarter.

These differences do not exist in the Juvenile and especially the Senior categories where the data are more homogeneous. In the case of the Senior and Juvenile categories there is no significant difference in the quarterly frequency of birth. In the Seniors the highest percentage was recorded in the fourth quarter $(36.73 \%)$ and the lowest in the third $(16.33 \%)$.

The total results for distribution of birth dates per half year show a significant difference $\left(\chi^{2}=10.44 ; p<0.01\right)$ with a greater frequency of players born in the first half of the year $(62.73 \%)$ compared to those born in the second $(37.27 \%)$.

If this analysis is carried out by competitive categories we can see that in three categories (Junior, Juvenile and Promising Talents) the highest percentage is revealed in the first half of the year. There are significant differences when the half year rate of births is compared with that of the standard population in the case of the Junior $\left(\chi^{2}=10.08 ; p<0.01\right)$ and Promising Talents $\left(\chi^{2}=7.26 ; p<0.01\right)$ categories.

The only case in which the frequency of births is greater in the second half of the year $(53.06 \%)$ compared to the first $(46.94 \%)$ is in the Senior category although the difference is not significant.

The results on the birth rate for even and odd numbered years are shown in Figure 1. 


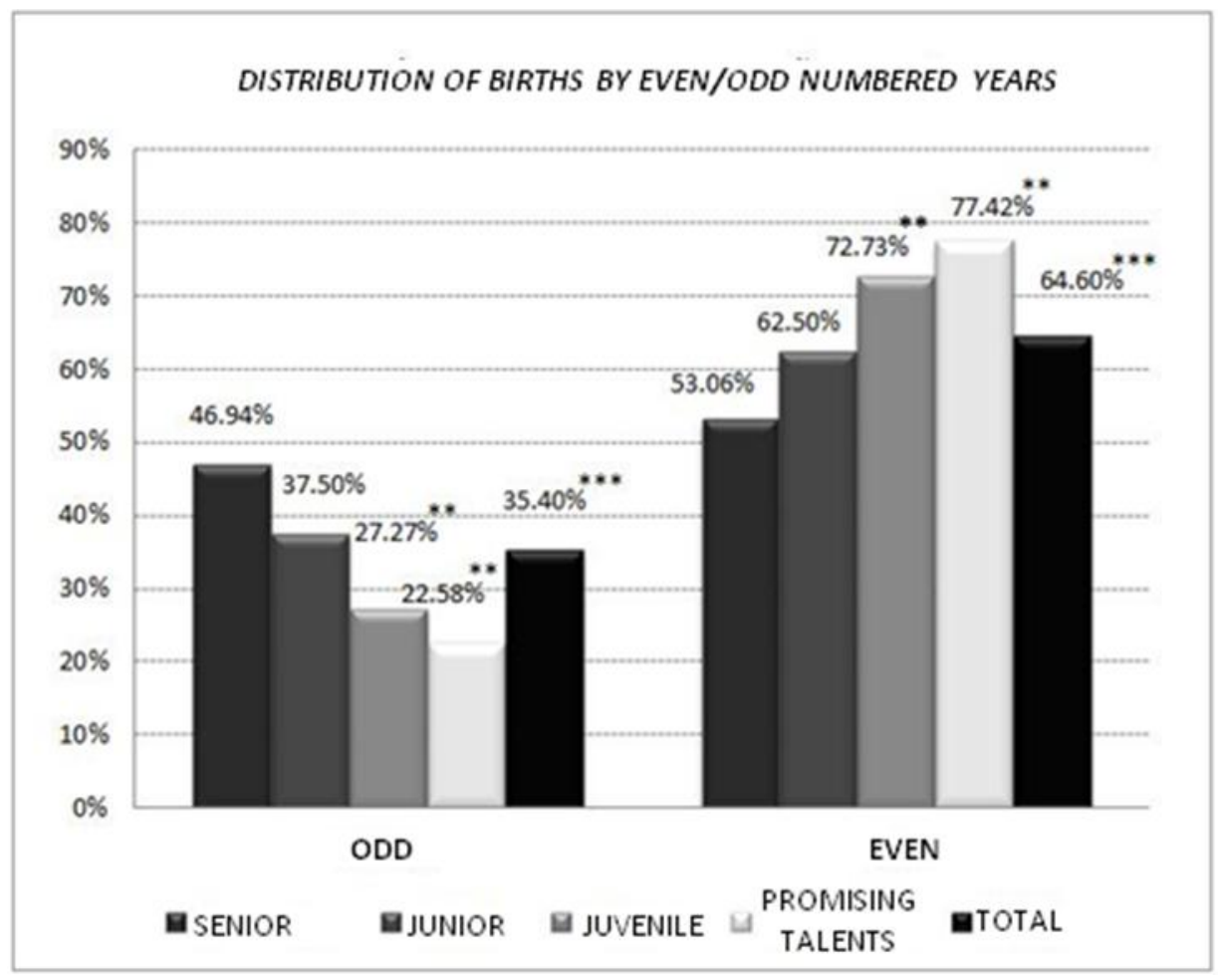

Figure 1. Data on the distribution of births per year $\left({ }^{* *}=p<0.01 ;{ }^{* * *}=p<0.001\right)$.

With regard to the births recorded in an even or odd numbered year, taking the total number of players studied ( $n=161)$, it can be seen that significant differences exist when comparing the annual birth rate for even $(64.60 \%)$ and odd $(35.40 \%)$ numbered years with those for the standard population $\left(\chi^{2}=13.72\right.$; $p<0.001)$. This difference is not evident at all the competitive levels but is equally significant at the juvenile $\left(\chi^{2}=6.81 ; p<0.01\right)$ and promising talents $\left(\chi^{2}=9.32 ; p<0.01\right)$ levels.

The non-existence of these differences at the junior and senior level is worthy of note as the data on even or odd numbered years are very similar. At the senior level $53.06 \%$ were born in an even numbered year and $46.94 \%$ in an odd numbered year.

\section{DISCUSSION}

The results of this study show that the RAE can be observed in the Spanish international handball players in the youngest category (Promising Talents) and in the junior category while the senior and juvenile categories do not show its influence. These results coincide with those found in the German men's national handball teams (Schorer et al., 2009). In fact, there are clear similarities between the Spanish men's senior national handball team and the German one.

The predominance of the frequency of birth dates in the first quarter and first half of the year, found in our study in the base categories, coincides with the findings of Romann \& Fuchslocher (2011) in the case of players in the Swiss national football team and by Williams (2010) in football players participating in the FIFA U17 World Cup competition. Romann \& Fuchslocher (2011) found significant differences in the 
distribution of birth dates from the under $15 \mathrm{~s}$ category to the under 19s category, with the under $18 \mathrm{~s}$ category revealing the greatest difference: $76 \%$ of the players had been born in the first half of the year. In our case this same tendency was seen in the categories of Promising Talents and Junior but not in the Juvenile category. This discrepancy between our results and those of Romann \& Fuchslocher (2011) may be due to the particular characteristics of the sports specialities studied, as well as the number of subjects analyzed. Their study was carried out on 630 base level players in the Swiss national football teams, while we studied 112 base level players from the Spanish national handball teams (Junior, Juvenile and Promising Talents categories). In the same way, Williams (2010) after analyzing all the participants in the 6 editions of the FIFA U17 World Cup Competition over a period of 10 years, found that the majority of players had been born in the first months of the year (36\% in the first quarter compared with 19\% in the last quarter of the year). The data from our study coincide with the analysis carried out by Williams (2010) revealing that in the category which we studied of under $17 \mathrm{~s}$, the Promising Talents category (15-16 years), the highest frequency of births was in the first quarter (41.94\%) compared with $6.45 \%$ in the last quarter of the year.

Like Gutiérrez et al. (2012) and Sánchez-Rodríguez et al. (2012) we found differences depending on the year of birth. In the general data analyzing the whole population we coincide with the study by Gutiérrez et al. (2012) in that there is a greater frequency, with a statistically significant difference, of players born in an even numbered year compared with those born in an odd numbered year. The differences between the results of both studies appear when the birth frequencies are analyzed in detail according to category. In the case of Gutiérrez et al. (2012), who analyzed the population of international women's handball players, the differences appeared in the Juvenile and Junior categories but not in the Senior one. In our case with Spanish international men's handball players we found a significantly different frequency in the Juvenile category but not in the Juniors or Seniors. It should be pointed out that in both studies there was a greater percentage of births in the even numbered years although there was no similarity in the categories in which this difference reached statistical significance. This difference in the results can be explained by the different number of subjects analyzed in both studies. For example in the Junior category Gutiérrez et al. (2012) analyzed the data on 363 subjects compared with the 48 subjects in our study.

This predominance of the frequency of international handball players born in an even numbered year may be justified by the selection system which was established by the International Handball Federation (IHF) for base level categories in the World Championships. The organization criteria are based on the registration of the players born in two consecutive years in the same category, starting the cut off date with those born in an even numbered year. For two seasons these participants remain in the same category, and at the end of these two years the whole group moves up to the following category. So the players who were born in an even numbered year will always be the oldest of that generation, while the players born in an odd numbered year will always be the youngest in the group (Gutiérrez et al., 2012).

It is currently believed that one of the main processes which are influenced by the RAE are the talent spotting and selection programmes (Sherar et al., 2007), due to the fact that these programmes look for players from whom they can obtain a better performance in the short term, to the detriment of players who will give a better performance in the long term; and the comprehensive development of the latter takes second place (Helsen et al., 2005). The players selected for this type of programmes are predominantly those who were born in the first months of the year because they are considered to be talented players (Musch \& Grondin, 2001) and are seen as being the best (Nolan \& Howell, 2010). However, Schorer et al. (2009) did not find significant differences in technical ability, anthropometric measurements and RAE in 
handball players of 13 to 15 years of age. This is why the causes of this effect and its consequences both in base level sport and in elite sport, in the short, medium and long term should be studied in more depth.

We should point out that the study of the RAE is at present producing new conclusions like those that can be taken from the study of the importance of the specific playing position for understanding the RAE in handball (Schorer et al., 2009; Sánchez-Rodríguez et al., 2012; Schorer et al., 2009; Schorer et al., 2009). Consequently we consider that it is important to look further into this variable in future studies.

\section{CONCLUSIONS}

On the basis of the results recorded and analyzed it can be concluded that there is an RAE in the base level categories in the Spanish men's national handball teams with regard to the quarter, half and even the year of birth (even or odd numbered), with little knowledge about the causes and consequences that this effect can provoke.

The influence of this RAE is not similar in all the age categories studied with a degree of homogeneity in the Senior category.

A practical aspect to be borne in mind in the process of talent spotting and selection for the Spanish national men's handball teams is that actions should be taken to decrease this RAE.

\section{REFERENCES}

1. BAKER J, SCHORER J, COBLEY S, BRÄUTIGAM H, BÜSCH D. Gender, Depth of Competition and Relative Age Effects in Team Sports. Asian Journal of Exercise and Sports Science. 2009; 6(1):1-7.

2. DELORME N, BOICHE J, RASPAUD M. The relative age effect in elite sport: the French case. Res $Q$ Exercise Sport. 2009; 80(2):336-344.

3. DELORME N, CHALABAEV A, RASPAUD M. Relative age is associated with sport dropout: evidence from youth categories of French basketball. Scand J Med Sci Spor. 2011; 21(1):120-128.

4. DELORME N, RASPAUD M. The relative age effect in young French basketball players: a study on the whole population. Scand J Med Sci Spor. 2009; 19(2):235-242.

5. DIXON J, HORTON S, WEIR P. Relative Age Effects: Implications for Leadership Development. International Journal of Sport \& Society. 2011; 2(2):1-15.

6. GUTIÉRREZ O, SAAVEDRA JM, CONTRERAS J, FERNÁNDEZ JJ. Influencia del año de nacimiento de una jugadora en las posibilidades de ser captada como talento en el balonmano femenino internacional. Apunts: Educación física y deportes. 2012; 2(108):54-62.

7. HELSEN W, VAN WINCKEL J, WILLIAMS AM. The relative age effect in youth soccer across. Eur J Sci Sport. 2005; 23(6):629-636.

8. LIDOR R, CÔTÉ J, ARNON M, ZEEV A, COHEN-MAOZ S. Relative Age and Birthplace Effects in Division 1 Players -- Do They Exist in a Small Country? Talent Development \& Excellence. 2010; (2):181-192.

9. MALINA RM. Physical growth and biological maturation of young athletes. Exercise Sport Sci $R$. 1994; 22:389-433.

10. MUJIKA I, VAEYENS R, MATTHYS SP, SANTISTEBAN J, GOIRIENA J, PHILIPPAERTS R. The relative age effect in a professional football club setting. J Sport Sci. 2009; 27(11):1153-1158. 
11. MUSCH J, GRONDIN S. Unequal competition as an impediment to personal development: a review of the relative age effect in sport. Dev Rev. 2001; 21(2):147-167.

12. NAKATA H, SAKAMOTO K. Relative age effect in Japanese male athletes. Percept Motor Skill. $2011 ; 113(2): 570-574$.

13. NOLAN JE, HOWELL G. Hockey success and birth date: The relative age effect revisited. Int Rev Sociol Sport. 2010; 45(4):507-512.

14. OKAZAKI FHA, KELLER B, FONTANA FE, GALLAGHER JD. The Relative Age Effect Among Female Brazilian Youth Volleyball Players. Res Q Exercise Sport. 2011; 82(1):135-139.

15. ROMANN M, FUCHSLOCHER J. Influence of the Selection Level, Age and Playing Position on Relative Age Effects in Swiss Women's Soccer. Talent Development \& Excellence. 2011; 3(2):239247.

16. SÁNCHEZ-RODRÍGUEZ C, YÁÑEZ A, SILLERO M, RIVILLA-GARCÍA J. El efecto relativo de la edad en el balonmano de élite masculino en España. [The relative age effect in the Spanish elite male handball]. EBM.RECIDE. 2012; 8(3):181-190.

17. SCHORER J, BAKER J, BÜSCH D, WILHELM A, PABST J. Relative age, talent identification and youth skill development: Do relatively younger athletes have superior technical skills? Talent Development \& Excellence. 2009; 1(1):45-56.

18. SCHORER J, BAKER J, LOTZ S, BÜSCH D. Influence of early environmental constraints on achievement motivation in talented young handball players. Int J Sport Psychol. 2010; 41(1):42-57.

19. SCHORER J, COBLEY S, BUSCH D, BRAUTIGAM H, BAKER J. Influences of competition level, gender, player nationality, career stage and playing position on relative age effects. Scand J Med Sci Spor. 2009; 19(5):720-730.

20. SHERAR LB, BAXTER-JONES A, FAULKNER RA, RUSSELL KW. Do physical maturity and birth date predict talent in male youth ice hockey players? J Sport Sci. 2007; 25(8):879-886. 